\title{
Multiple microemboli after disintegration of clot during thrombolysis for acute myocardial infarction
}

\author{
P J Stafford, C J L Strachan, R Vincent, D A Chamberlain
}

\begin{abstract}
Seven of 475 consecutive patients treated with thrombolysis for acute myocardial infarction had severe embolic complications that were believed to be caused by disintegration of pre-existing clot. Three patients had symptoms that persisted for many weeks, and five died. Any potential site of preexisting blood clot within the vascular system, notably an enlarged left atrium, ventricular aneurysm, or aortic aneurysms, should be regarded as a contraindication to treatment with thrombolytic agents.
\end{abstract}

\section{Introduction}

The most important complications of thrombolytic treatment are due to haemorrhage'; this may be inevitable because a physiological haemostatic plug and an unwanted thrombus present the same substrate for thrombolytic agents. Reperfusion injury is another direct consequence of thrombolysis. ${ }^{2}$ We observed a third complication associated with disintegration of clots after treatment with anistreplase or streptokinase, and we report on seven patients who had severe symptoms due, we believe, to multiple emboli from the disintegration of pre-existing thrombus in the heart or large arteries.

\section{Case reports}

Our policy in this hospital has been to treat all patients presenting with acute myocardial infarction with thrombolytic agents unless they have important contraindications. In addition, all patients are given anticoagulant treatment with heparin, the first dose being within six hours after thrombolytic treatment. In cases 1-5 reported below warfarin was also given, with the first dose within 24 hours after admission. The table gives details of the cases.

Case 1-A 62 year old woman developed exquisitely painful lower legs 48 hours after thrombolytic treatment for an acute inferior myocardial infarction. The skin of her lower legs showed widespread mottling and discoloration but her peripheral pulses were normal. Doppler studies of her legs and tests for autoantibodies and anticardiolipin antibodies showed no abnormalities, and her erythrocyte sedimentation rate was normal. Computed tomography of her legs did

BrMed f 1989;299:1310-2

Clinical details of seven cases in which microembolic complications occurred after thrombolytic treatment with anistreplase or streptokinase

\begin{tabular}{|c|c|c|c|c|c|c|}
\hline $\begin{array}{c}\text { Case } \\
\text { No }\end{array}$ & $\begin{array}{c}\text { Age } \\
\text { (years) }\end{array}$ & $\begin{array}{l}\text { Time from } \\
\text { thrombolysis } \\
\text { (hours) }\end{array}$ & $\begin{array}{l}\text { Site of } \\
\text { infarct }\end{array}$ & $\begin{array}{l}\text { Site of } \\
\text { emboli }\end{array}$ & Source of emboli & Outcome \\
\hline 1 & 62 & 48 & Inferior acute & Legs & Unknown & Recovery \\
\hline 2 & 62 & 6 & Inferior acute & Leg & Aortic aneurysm & Death \\
\hline 3 & 69 & 1 & Lateral acute & Brain & Left atrium & Death \\
\hline 4 & 69 & 12 & Anterior acute & Systemic & Unknown & Death \\
\hline 5 & 70 & $72-120^{\star}$ & Inferior acute & Legs & Popliteal aneurysm & Recovery \\
\hline 6 & 57 & 6 & Anterior acute & Brain, legs & $\begin{array}{l}\text { Left ventricle } \\
\text { (aortic aneurysm) }\end{array}$ & Death \\
\hline 7 & 57 & 4 & Anterior acute & Brain & Unknown & Death \\
\hline
\end{tabular}

*Symptoms noticed by patient at three days but were not obtrusive until five days after treatment. not show any evidence of muscle infarction (muscle type creatine kinase activity was not measured). Anticoagulation with warfarin was continued and, although walking was very painful for several weeks, her symptoms had settled over the following four months.

Case 2-A 62 year old man with a history of ischaemic heart disease developed a painful, acutely ischaemic, lower left leg six hours after thrombolytic treatment for an inferoposterior myocardial infarction. His left femoral artery was enlarged and no distal pulses were palpable. Before further intervention could be attempted cardiogenic shock, which did not respond to treatment with inotropic agents, supervened. He died 24 hours after admission. Necropsy showed severe atherosclerosis of the aorta and great vessels with a large abdominal aortic aneurysm, full of friable thrombus. Antemortem clot was present in the left femoral artery.

Case 3-A 69 year old woman with mixed mitral valve disease, biventricular failure, and atrial fibrillation developed a left sided hemiparesis an hour after thrombolytic treatment for a high lateral myocardial infarction. Computed tomography of the brain disclosed a right sided non-haemorrhagic cerebral infarct; echocardiography showed a thickened mitral valve with reduced excursion and an enlarged left atrium without discernible thrombus. Anticoagulation with warfarin was continued. Her subsequent progress was initially encouraging, with rapid recovery from the hemiparesis, but on the fourth day after admission she had a cardiac arrest. Necropsy confirmed mitral stenosis and myocardial infarction with recent ventricular rupture. No evidence of residual clot in the atria was reported.

Case 4-A 69 year old man developed severe pain in the lower abdomen, radiating to both legs, about 12 hours after thrombolytic treatment for an anterior myocardial infarction. His lower trunk and legs subsequently became cyanotic and discoloured with a well defined line of demarcation. His renal function deteriorated, and refractory left ventricular failure developed. Despite continuing anticoagulation with warfarin the skin discoloration persisted and areas of skin infarction developed. Skeletal muscle creatine kinase activity was extremely high. Abdominal ultrasonography did not disclose any evidence of retroperitoneal bleeding or abdominal aortic aneurysm. After a prolonged illness he died after an asystolic cardiac arrest. Necropsy was not permitted.

Case 5-A 70 year old man developed intermittent claudication at $18 \mathrm{~m}$ after thrombolytic treatment for an inferior myocardial infarction, which became obtrusive as he was becoming mobile five days later. His lower legs were mottled and discoloured and the calves were tender. His renal function became increasingly impaired (peak plasma creatinine concentration $263 \mu \mathrm{mol} / \mathrm{l}$ ) and activities of muscle enzymes were increased. The pulses in his feet were well preserved and Doppler pressures in the distal legs were normal, although poor capillary return was noted in his toes. A vasculitic reaction to anistreplase ${ }^{3}$ was suspected, although his history was not typical. Treatment 
with steroids was started and anticoagulation with warfarin continued. Determination of antistreptolysin O titre, hepatitis B antigen, rheumatoid factor, complement, cryoglobulins, and immunoglobulins and an autoantibody screen, protein electrophoresis, microscopic examination of urine, and serological testing for syphilis gave normal results. The concentration of circulating immune complexes was increased $(60$ $\mathrm{mg} / \mathrm{l}$; normal range $<20 \mathrm{mg} / \mathrm{l}$ ), and the peak erythrocyte sedimentation rate was only $30 \mathrm{~mm}$ in the first hour. The patient's rash and tenderness of his calves improved after steroid treatment, and he was discharged home. Two days later he was readmitted with a recurrence of his symptoms; the toes of both feet had become markedly ischaemic and web space flow measured by Doppler ultrasonography was negligible. Ultrasonography showed a normal abdominal aorta but appreciable widening of the popliteal arteries, suggesting a diagnosis of microemboli to the distal legs from aneurysms of the popliteal arteries. After six infusions of iloprost, a stable analogue of epoprostenol, ${ }^{+}$ at a dose of $1 \mathrm{ng} / \mathrm{kg} / \mathrm{min}$, increasing to $2 \mathrm{ng} / \mathrm{kg} /$ min, the clinical condition of his feet improved rapidly and web space flow increased. The improvement was not fully sustained and a further admission for treatment with iloprost was required. Renal function remained mildly impaired six weeks after presentation. He made a full recovery after two months.

Case 6-A 57 year old man had thrombolytic treatment with anistreplase for an anterior myocardial infarction. He had a history of myocardial infarction. Six hours after treatment he became confused and complained of extremely painful legs. His lower abdomen and legs were mottled, with absent femoral pulses. Ultrasonography of the abdomen did not show any evidence of abdominal aortic aneurysm. Echocardiography disclosed a dilated, hypokinetic left ventricle with an apical aneurysm that did not seem to contain thrombus. Before computed tomography of the brain could be performed his neurological state suddenly deteriorated and he died. Necropsy showed left ventricular mural thrombus with multiple cerebral infarcts and one large haemorrhage. The infrarenal portion of the aorta was aneurysmal and contained antemortem thrombus.

Case 7-A 57 year old man collapsed suddenly four hours after thrombolysis with streptokinase for an anterior myocardial infarction that had probably occurred 19 hours previously. He had clinical evidence of brain stem infarction, and computed tomography showed multiple cerebral infarcts, consistent with multiple emboli, but no evidence of intracerebral haemorrhage. He died 13 days later without any evidence of neurological improvement. Necropsy was not permitted. No site of thrombus was identified.

\section{Discussion}

The seven patients described all had serious complications that we believe were due to systemic embolisation from disintegration of a pre-existing clot. The diagnosis cannot readily be proved. We think it is important, however, to draw attention to a pattern of events that we have seen fairly frequently only in association with thrombolysis, and believe that our experience is relevant to decisions about selecting cases for this important treatment.

Our seven cases were noted during a period when 475 patients were given thrombolytic treatment, an incidence of $1 \cdot 5 \%$. Multiple emboli from disintegration of the clot may therefore be an important, though fairly uncommon, complication.

We have no reason to believe that any one thrombolytic agent is more likely than others to cause this problem. Six cases occurred after anistreplase treatment and one after streptokinase. This ratio probably reflects our differential use of the two drugs over the period in question. The presence of fresh clot rather than organised clot is probably the most important determinant of risk. Care in selecting cases should reduce the incidence of microemboli, though vulnerability to this risk could not have been predicted in all our patients.

The evidence to support our diagnosis is persuasive. Five of the seven patients complained of severe leg pain yet only two lost a major pulse. An actual or potential source of pre-existing clot was identified in three of these five, and in one who lost a pulse there was definite necropsy evidence of lysis of the clot. Cold, mottled skin without loss of pulses, affecting the lower trunk and legs but sparing the upper body seems to be characteristic and is difficult to explain on other grounds. Our three patients with cerebrovascular accidents developed catastrophic symptoms within hours after treatment. Two had evidence of brain infarction without haemorrhage. The third had evidence of multiple infarcts with a haemorrhage that was probably a secondary event; he also had sudden and typical manifestations of lower body ischaemia with proved pre-existing clot in the left ventricle and the aorta.

With the possible exception of case 7 , the events described are unlikely to have resulted from left ventricular thrombus secondary to the infarction. Serial echocardiographic studies have shown that mural thrombus is uncommon in inferior myocardial infarction $^{56}$ and only rarely develops in the first 72 hours after anterior myocardial infarction. ${ }^{5}$ Embolic events tend to occur late, and multiple emboli are rare. ${ }^{6}$ It is important that in five of our seven cases symptoms occurred within 12 hours after thrombolysis. An alternative explanation for the widespread effects seen in cases $1,4,5$, and 6 is a vasculitic reaction. But in no case was the clinical picture typical of the syndrome that we have described previously after treatment with anistreplase, ${ }^{3}$ although this diagnosis was entertained briefly in one case. The skin, when affected, was mottled, with patchy ischaemia rather than a purpuric rash. Pain was not a feature in our patients with vasculitis. In one case the concentration of circulating immune complexes was increased. As these are not routinely measured after uncomplicated thrombolysis we do not know if this is of any importance.

We are not aware of any reports of microembolic phenomena after the use of anistreplase, although anecdotal reports have associated streptokinase with microscopic evidence of cholesterol emboli. ${ }^{7}$ The mechanism proposed is that thrombolysis removes thrombus overlying atheromatous plaques, thus allowing cholesterol debris to enter the bloodstream. ${ }^{8}$ This process may have been responsible for some of the cases reported above, but in others it seems certain that fragments of the lysed clot itself were responsible for the subsequent embolic event. We noted that fibrinogen concentrations were increased in three of five cases in which it was measured whereas thrombolytic agents usually reduce the levels of circulating fibrinogen. ${ }^{9}$ Hyperfibrinogenaemia was also noted in a previous report of a cerebral embolus after thrombolytic treatment with streptokinase. ${ }^{10}$ This may be a chance finding, but we suggest that fibrinogen should be measured in other similar cases.

The strikingly beneficial effect of iloprost in case 5 suggests that this agent may be useful in treating peripheral microemboli. It is effective in other occlusive diseases of small vessels such as Raynaud's phenomenon in scleroderma, ${ }^{11}$ although the pathology of the two conditions has little in common.

The complication of multiple systemic emboli from 
disintegration of clots seems to have a high mortality and important morbidity. We suspect that cases have often masqueraded under other diagnostic labels. Presentation is usually within 24 hours after thrombolytic treatment, and treatment at this stage with anticoagulation and prostaglandin analogues may be beneficial. We recommend that patients considered for thrombolytic treatment should be examined for conditions associated with intravascular clot. Thus ventricular aneurysm, aneurysm of the aorta or of other large arteries, and mitral valve disease with atrial fibrillation may be contraindications for thrombolysis. We emphasise, however, that patients should not be denied the benefits of myocardial salvage and the potential reduction in mortality that can be achieved with thrombolytic treatment ${ }^{12}$ unless the associated risks are appreciable.

We thank Schering Health Care for supplying iloprost in case 5.

1 Rao AK, Pratt C, Berke A, et al. Thrombolysis in myocardial infarction (TIMI) trial. Phase I: hemorrhagic manifestations and changes in plasma fibrinogen and the fibrinolytic system in patients treated with recombinant tissue plasminogen activator and streptokinase. $\mathcal{A}$ Am Coll Cardiol 1988;11: $1-11$
2 Mathey DG, Schofer J, Kuck Beil U, Kloppel G. Transmural, haemorrhagic myocardial infarction after intracoronary streptokinase. Clinical, angiomyocardial infarction after intracoronary streptokinase.
graphic and necropsy findings. Br Heart 1982 $_{108}$ : $546-51$

3 Bucknall C, Darley C, Flax J, Vincent R, Chamberlain D. Vasculitis complicating treatment with intravenous anisoylated plasminogen streptokinase activator complex in acute myocardial infarction. $\mathrm{Br}$ Heart $\mathcal{f}$ 1988;59:9-11.

4 Rademaker M, Thomas RHM, Provost G, Beacham JA, Cooke ED, Kirby JDT. Prolonged increase in digital blood flow following iloprost infusion in patients with systemic sclerosis. Postgrad Med J 1987;63:617-20.

5 Weinreich DJ, Burke JF, Pauletto FJ. Left ventricular mural thrombi complicating acute myocardial infarction. Ann Intern Med 1984;100:789-94.

6 Stratton JR, Resnick AD. Increased embolic risk in patients with left ventricular thrombi. Circulation 1987:75:1004-11.

7 Pirson Y, Honhon B, Cosyns JP, Van Ypersele C. Cholesterol embolism in a renal graft after treatment with streptokinase. Br Med f 1988;296:394-5.

8 Glassock RJ, Ritz E, Bommer J, Andrassy K, Waldherr R. Acute renal failure, hypertension and skin necrosis in a patient with streptokinase therapy. Am f Nephrol 1984:4:193-200.

9 Lew AS, Cercek B, Hod H, Shah PK, Ganz W. Usefulness of residual plasma fibrinogen after intravenous streptokinase for predicting delay or failure of reperfusion in acute myocardial infarction. Am $\mathcal{F}$ Cardiol 1986;58:680-5.

10 Dejaeger P, Van De Werf F, Vermylen J, De Geest H. Thromboembolic complication after streptokinase therapy of pulmonary emboli. Acto Cardiologica (Brux) 1988;43:61-5.

11 Rademaker $M$, Cooke ED, Almond NE, et al. Comparison of intravenou infusions of iloprost and oral nifedipine in treatment of Raynaud's phenomenon in patients with systemic sclerosis: a double blind randomised study. Br Med f 1989;298:561-4.

12 Julian DG Pentecost BL Chamberlain DA. A milestone for myocardia infarction. BrMed f 1988;297:497-8.

(Accepted 29 September 1989)

\title{
Neuropathology of HIV infection in haemophiliacs: comparative necropsy study
}

\author{
M M Esiri, F Scaravilli, P R Millard, J N Harcourt-Webster
}

Departments of

Neuropathology and

Clinical Neurology,

Radcliffe Infirmary, Oxford

OX2 6HE

M M Esiri, DM, clinical reader in neuropathology

\section{Department of}

Neuropathology, Institute

of Neurology, London

WC1

F Scaravilli, MD, reader

\section{Department of}

Histopathology,

John Radcliffe Hospital,

Oxford

P R Millard, MD, consultant

histopathologist

Department of

Histopathology,

St Stephen's Hospital,

London SW10 9TH

J N Harcourt-Webster, MD,

consultant histopathologist

Correspondence and

requests for reprints to:

Dr Esiri.

BrMed f 1989;299:1312-5

\section{Abstract}

Objective-To discover whether pathological and neuropathological findings at necropsy are different in haemophiliacs and other subjects positive for HIV.

Design-Pathological and neuropathological findings at necropsy were compared in haemophiliacs and non-haemophiliacs, most of them homosexual men.

Setting-Necropsies performed in the south of England.

Subjects-11 Haemophiliacs (mean age 41, range 15-69) and 31 non-haemophiliacs, 29 of whom were homosexual men (mean age 40, range 21-60). AIDS was diagnosed before death in four haemophiliacs and all but one of the non-haemophiliacs.

Main outcome measures-Prevalence of various forms of neuropathology and systemic pathology in the haemophiliacs and non-haemophiliacs, compared with Fisher's exact test.

Results-The prevalences of opportunistic infections of the central nervous system were significantly higher in the non-haemophiliacs (cerebral toxoplasmosis $23 \%$ (7), progressive multifocal leucoencephalopathy $10 \%(3)$, and cerebral cytomegalovirus infection $19 \%(6)$ in the non-haemophiliacs $v$ no cases in the haemophiliacs). The prevalences of fresh and old intracranial haemorrhages and cirrhosis of the liver were significantly higher in the haemophiliacs (fresh intracranial haemorrhage $\mathbf{4 5 \%}$ (5), old intracranial haemorrhage $36 \%(4)$, and cirrhosis of the liver $27 \%$ (3) in the haemophiliacs $v$ no cases in the non-haemophiliacs). The prevalence of neuropathological changes in the non-haemophiliacs was similar to that found in other necropsy series.

Conclusions - The main causes of death in haemophiliacs positive for HIV included intracranial haemorrhage and cirrhosis of the liver. The haemo- philiacs died when the characteristic neuropathological changes associated with HIV infection were at a fairly early stage in their development.

\section{Introduction}

Neuropathological studies in North America and Europe of patients dying of AIDS have shown a variety of changes, including an encephalopathy or encephalitis associated with multinucleated giant cells in $25-30 \%$ of cases. ${ }^{1-5}$ In addition, there may be lesions due to opportunistic infections or lymphomas. In most of the necropsy series reported most cases of infection with HIV occurred in homosexual men and drug abusers. Haemophiliacs with HIV infection acquired from infected blood products have generally formed a small proportion of the total cases reported, and there has been no clear indication of whether the neuropathology in these subjects differs from that in other groups at risk. We present the results of neuropathological examination at necropsy in a series of subjects infected with HIV that included a fairly high proportion of haemophiliacs $(25 \%)$.

\section{Subjects and methods}

We examined brains from 42 subjects known to have had antibodies to HIV. Eleven were haemophiliacs, 29 were known to have been homosexual, one was the husband of a drug addict, and one was a nurse from Zambia. All but one were men. The mean age of the haemophiliacs was 41 years (range 15-69) and that of the non-haemophiliacs 40 years (21-60). The duration for which the haemophiliacs were known to have had HIV antibodies varied between nine and 48 months (mean 31 months) and for the other subjects from nil to 48 months (mean 15 months). Agreed criteria for the clinical diagnosis of AIDS $^{6}$ were met in four of the haemophiliacs and in all but one of the other subjects. 